\title{
Effect of Fillers on Mechanical Properties and Fracture Toughness of Glass Fabric Reinforced Epoxy Composites
}

\author{
Basappa Hulugappa, Mysuru V. Achutha, Bheemappa Suresha \\ Department of Mechanical Engineering, The National Institute of Engineering, Mysore, India \\ Email: sureshab2004@yahoo.co.in
}

Received 23 November 2015; accepted 10 January 2016; published 13 January 2016

Copyright (C) 2016 by authors and Scientific Research Publishing Inc.

This work is licensed under the Creative Commons Attribution International License (CC BY). http://creativecommons.org/licenses/by/4.0/

(c) (i) Open Access

\begin{abstract}
Plain weave woven glass fabric reinforced epoxy (G-E) composite filled with two different types of fillers namely graphite, silicon carbide (each 5 and $10 \mathrm{wt} \%$ ) was fabricated by hand lay-up method and compressed using hot press. These composites were investigated for their static mechanical properties such as tensile, flexural properties and impact strength as well as mode-I fracture toughness as per ASTM standards. Experimental results on mechanical properties indicate that the strength and the modulus in tensile and flexural mode for G-E composite increase with increasing filler loading. The unfilled G-E composite has the tensile strength of $305 \mathrm{MPa}$ and increased to 404.2 MPa for $10 \mathrm{wt} \%$ silicon carbide. However, in three-point bend mode, addition of graphite in G-E showed the highest flexural strength as well as modulus. Mode-I fracture toughness test results indicated that the graphite filler loading improved the toughness of G-E composite. Selected failed samples under tensile, bending and mode-I fracture were examined using scanning electron microscope to identify the fracture features.
\end{abstract}

\section{Keywords}

G-E Composite, Fillers, Mechanical Properties, Fracture Toughness

\section{Introduction}

Fiber and/particulate filled polymer matrix composites (PMCs) are used in very large quantities in almost all engineering applications and despite the overwhelming interest in advanced PMCs, considerable research and development is done on hybrid PMCs even today. Functional fillers improve stiffness and heat deflection temperatures, decrease shrinkage, voids and good appearance of the composites [1].

The properties of particulate filled fiber reinforced PMCs are decided by component properties, composition,

How to cite this paper: Hulugappa, B., Achutha, M.V. and Suresha, B. (2016) Effect of Fillers on Mechanical Properties and Fracture Toughness of Glass Fabric Reinforced Epoxy Composites. Journal of Minerals and Materials Characterization and Engineering, 4, 1-14. http://dx.doi.org/10.4236/immce.2016.41001 
structure and fiber/filler-matrix interaction [2] [3]. Matrix cracks and fiber fracture play an important role in laminates under tensile load. Delamination may be found due to a wide variety of foreign object impact damage, poor fabrication process, and fatigue from environment cycle. Composites offer two impending advantages over monolithic materials. First, polymer composites offer additional energy-absorbing damage modes, making them attractive for lightweight, impact resistant applications. Indeed for use in conventional (opaque) armor systems, composites have enabled a significant increase in toughness [4]. Second, composites would offer engineers more flexibility in designing transparent laminates, allowing for the manipulation of constituent properties and volume fraction in order to tune the acoustic impedance of composite layers and thus how stress waves propagate through the laminate from one layer to the adjacent layer [5].

Particulate filled polymer composites modify the physical and mechanical properties in many ways [6]-[9]. To deal with the obvious limitations of polymers, for example, low stiffness and low strength, and to expand their applications in different sectors, inorganic particulate fillers, such as $\mathrm{SiO}_{2}, \mathrm{Al}_{2} \mathrm{O}_{3}$, graphite, TiO fly ash particles, glass beads, short glass fibers, are often reinforced to process polymer composites, which normally combine the advantages of their constituent phases. Stiffness can be readily improved by adding micron sized particles since rigid inorganic particles generally have a much higher stiffness than that of polymer matrices [10]-[12]. However, the strength strongly depends on the stress transfer between the particles and the matrix. For well-bonded particles, the applied stress can be effectively transferred to the particles from the polymer matrix resin [13]; this clearly improves the strength [14]-[17]. However, for poorly bonded micro-particles, strength reduction occurs [18] [19]. The drawback of thermosetting resins is their poor resistance to crack growth [20] [21]. But inorganic particles have been found to be effective toughness for thermosetting resins [22].

Currently, glass fiber is the typical reinforcing material for thermoset matrices for various structural applications. Woven fabric reinforced epoxy composites are well known for their high ratios of strength and stiffness to weight in orthotropic direction. These attractive characteristics of the composites have resulted in numerous applications of the materials in areas where high performance and light weight of structures are essential [23]. Cho et al. [24] investigated the effects of particle size, particle matrix interface adhesion and particle loading on mechanical properties of PMCs. They concluded that the mechanical properties of PMCs depend strongly on the particle size, particle-matrix interface adhesion and loading. Particle size has an obvious effect on these mechanical properties. For example, smaller $\mathrm{CaCO}_{3}$ particles provide higher strength of filled polypropylene (PP) composites at a given particle loading. Mishra et al. [25] investigated the mechanical properties of glass fiber reinforced polymer composites. They have concluded that the tensile, flexural and impact properties fiber reinforced polyester composites are improved by the incorporation of small amount of glass fibers in these composites. Dong et al. [26] have studied the flexural and tensile moduli of S-2 glass and carbon fiber reinforced hybrid epoxy composites and they have concluded that more of glass fibers added into the composite reduce both the flexural and tensile moduli, but the presence of glass alone in epoxy stabilized the flexural modulus.

Hybrid PMCs are used in number of applications where high performance and light weight of structures are essential wherein, the mechanical performance of composites laminates in the out-of-plane direction is normally much lower than those in-plane directions which can result interlaminar fracture are delamination especially in composite laminates. Experimental determination of the fracture toughness associated with fibers and fillers as well as failure mode is extremely important for material characterization. Avci et al. [27] studied the fracture behavior of glass fiber reinforced polymer composite, with varying notch to depth ratio and different volume fraction of glass fiber and unsaturated polyester matrix. They revealed that the fracture toughness increased with increasing glass fiber content. Srivastva et al. [28] showed that the fracture toughness of epoxy matrix can be increased by adding fly ash particles. Srivastva and co-workers [29] also studied the fracture toughness of fly ash filled cross ply glass fiber reinforced epoxy composites. They found that the fracture toughness of fly ash filled composite is independent of initial crack length but dependent on the orientation of fiber, while toughness was improved by the addition of fly ash filler. Lenord et al. [30] investigated the fracture behavior of glass fiber-reinforced polyester composites. They showed that with increase in fiber content up to $60 \mathrm{wt} \%$ by enhanced the fracture toughness and critical energy released rate of the matrix. Moloney et al. [31] investigated the fracture properties of two commercial epoxide resins of both filled and unfilled with varying volume fraction of silica, alumina and dolomite particles. The changes in fracture toughness in the presence of the inclusions have been explained in terms of crack pinning mechanism. Hartikain et al. [32] have studied the fracture behavior of long glass fiber reinforced composite with $\mathrm{CaCO}_{3}$ as filler. They concluded that the addition of filler increased the stiffness. Further, they have shown that the fracture toughness of unreinforced composite remained unaf- 
fected. Naveed et al. [33] studied the mode-I interlaminar fracture behavior and mechanical properties of carbon fiber reinforced and nanoclay filled epoxy matrix composites. They found that organo-clay brought about a significant improvement in flexural modulus especially in the first few wt\% of loading also fracture toughness increased about $60 \%$ by the addition of $3 \mathrm{wt} \%$ clay. Soon et al. [34] studied the effect of compounding two different sized spherical silica particles (0.24 and $1.56 \mu \mathrm{m}$ in diameter) into bisphenol A-type epoxy matrix with a constant volume fraction of $30 \%$. They concluded that the varying the composition ratio of two silica particles did not significantly affect the bending elastic modulus, the bending strength and fracture toughness.

Based on the cited literature, it was found that combined constituents namely fiber and filler in thermoset polymer study showed improved mechanical properties and in some cases improved the fracture toughness. This study aims to investigate the role of hard filler and lubricating filler ( $\mathrm{SiC}$ and graphite) in E-glass woven fabric reinforced epoxy (G-E) composite. The static mechanical properties and mode-I fracture toughness of these composites were studied. Furthermore, the main goal of this research work is to recommend the best hybrid reinforced G-E composite for structural applications.

\section{Experimental and Methods}

\subsection{Materials}

Plain weave woven glass fabrics made of $360 \mathrm{~g} / \mathrm{m}^{2}$ containing E-glass fibers of diameter of about $12 \mu \mathrm{m}$ have been employed. The epoxy resin (LAPOX L-12) was mixed with the hardener (K-6, supplied by ATUL India Ltd., Gujarat, India). Two different fillers namely SiC and graphite (each 5 and 10 wt\%) were used in the present work. These fillers were silanated and have an average particle size of about $25 \mu \mathrm{m}$. Silicon carbide material was supplied by (Carborundum Universal Ltd., Chennai, India) and graphite powder was supplied by (Graphite India Ltd, Bengaluru, India.)

\subsection{Fabrication}

E-glass plain weave woven roving fabric which is compatible to epoxy resin was used as the reinforcement. The epoxy resin was mixed with the hardener in the ratio 100:10 by weight ratio. A hand lay-up method was used to for lay-up of lamina consolidation. Later, the consolidation was compressed and cured using hot press under 0.5 MPa pressure and temperature of $70^{\circ} \mathrm{C}$. In all the composites the amount of glass fiber was $55 \mathrm{wt} \%$. Eight and thirty three layers of fabrics were used to obtain laminate of thickness 3 and $10 \mathrm{~mm}$ respectively. The laminate so prepared has dimensions $500 \mathrm{~mm} \times 550 \mathrm{~mm} \times 10 \mathrm{~mm}$. Further, to prepare the particulate filled G-E hybrid composites, selected filler with a known quantity was mixed in the epoxy resin. The details of the G-E hybrid composites manufactured were listed in Table 1.

\subsection{Mechanical Characterizations}

The tensile and bending tests were carried out on a fully automated (Kalpak-100K) universal testing machine connected to a computer, which was aided by Kalpak-software. A 100/10-kN load cell was used and load versus deformation/deflection curves were collected for all the measurements. The tensile tests were performed according to ASTM D638 standard. The tensile test was performed at crosshead speed of $5 \mathrm{~mm} / \mathrm{min}$ (quasi-static). Tensile modulus was evaluated from the stress-strain diagram. Flexural testing under three-point bending mode was conducted in accordance with ASTM D 790. The span length was set at about $60 \mathrm{~mm}$. Testing speed was set at $2 \mathrm{~mm} / \mathrm{min}$ and the tests were carried out at room temperature and specimen dimensions are $90 \mathrm{~mm} \times 12$ $\mathrm{mm} \times 3 \mathrm{~mm}$. Flexural modulus was evaluated from the load-deflection curves.

Izod impact strength was performed according to ASTM D256 using (INSTRON) (Impact hammer with a mass of $7.5 \mathrm{~kg}$ ) impact testing machine at the striking rate of $3.46 \mathrm{~m} / \mathrm{s}$. The dimensions of the specimens were $60 \mathrm{~mm} \times 12 \mathrm{~mm} \times 3 \mathrm{~mm}$ size on one side surface of the specimen a V-notch have been made at an angle of $45^{\circ}$ with root depth of $2 \mathrm{~mm}$. At least five samples were tested for each composite type for all the studies and the average value was recorded.

\subsection{Mode-I Fracture Test}

The fracture toughness test were carried out using three point bending specimen having dimensions as shown in 
Table 1. Compositional details with sample code of the composites fabricate.

\begin{tabular}{cccc}
\hline Composition & Specimen Code & Epoxy wt\% & Filler wt\% \\
\hline Glass-Epoxy & G-E & 45 & - \\
Graphite Filled Glass-Epoxy & $5 \mathrm{Gr}+\mathrm{G}-\mathrm{E}$ & 40 & 35 \\
Graphite Filled Glass-Epoxy & 10Gr + G-E & 40 & 5 \\
Silicon Carbide Filled Glass-Epoxy & 5SiC + G-E & 35 & 10 \\
Silicon Carbide Filled Glass-Epoxy & 10SiC + G-E & & 5 \\
\hline
\end{tabular}

(Figure 1) as per the ASTM D5045-99. The specimen was carefully prepared by a milling cutter. The notch was cut initially by using hacksaw blade, and then a fresh razor blade was tapped at the notch to initiate a natural crack. The test was conducted using $100 \mathrm{kN}$ universal testing machine (Kalpak UTM) and the sample loaded in three-point bend mode as shown in (Figure 2). The monotonic loading during the test was applied at a constant displacement rate of $10 \mathrm{~mm} / \mathrm{min}$, and a minimum of three specimens were tested for each composite. The mode-I stress intensity factor $\left(K_{I C}\right)$ at the point fracture initiation was determined using Equation (1). The load displacement curve was plotted to evaluate the critical load $\left(P_{Q}\right)$. To determine the valid stress intensity factor, $\left(K_{I C}\right)$ a conditional result $K_{Q}$ was calculated using Equation (1)

$$
K_{Q}=\left(\frac{P_{Q}}{B W^{1 / 2}}\right) f(x)
$$

$B=$ specimen thickness in $\mathrm{mm} X=a / w$ where $(0>x>1)$.

$W=$ specimen width in mm.

$a=$ crack length in mm.

$$
f(x)=6 x^{1 / 2} \frac{\left[1.99-x(1-x)\left(2.15-3.93 x+2.7 x^{2}\right)\right]}{(1+2 x)(1-x)^{3 / 2}}
$$

$P_{Q}$ is determined by load-displacement graph. To ensure the plain strain condition, the size criteria is validated by the expression (3).

$$
B \cdot a(w-a)>2.5\left(\frac{K_{Q}}{\sigma_{y s}}\right)
$$

where $(w-a)$ the ligament and $\sigma_{y s}$ is the yield tress of the specimen. If $K_{Q}$ satisfies Equation (3) then $K_{Q}$ is equal to $K_{I C}$. The test specimens of unfilled and filled composites of failed samples are shown in the Figure 3 .

\section{Results and Discussion}

\subsection{Mechanical Properties}

The mechanical test data for unfilled G-E and particulate filled G-E hybrid composite are presented in Table 2. From this it is clear that the introduction of $\mathrm{SiC}$ and graphite fillers in G-E composite system increased the strength as well as modulus under tensile and flexure mode.

\subsubsection{Tensile Properties}

A summary of the tensile test data obtained are listed in Table 2. Several authors have reported improvement in tensile strength and modulus for glass-epoxy composites with increase in filler loading. [2] [3] [25] [26]. Generally, the G-E composite has lesser tensile strength than particulate filled G-E composites (Table 2). The silicon carbide filled G-E composite has a tensile strength of 404.2 MPa and a modulus of $13.1 \mathrm{GPa}$ compared to 305 $\mathrm{MPa}$ and 12.6 GPa of unfilled G-E composite. The addition of micron-sized fillers (SiC, graphite) enhanced the 


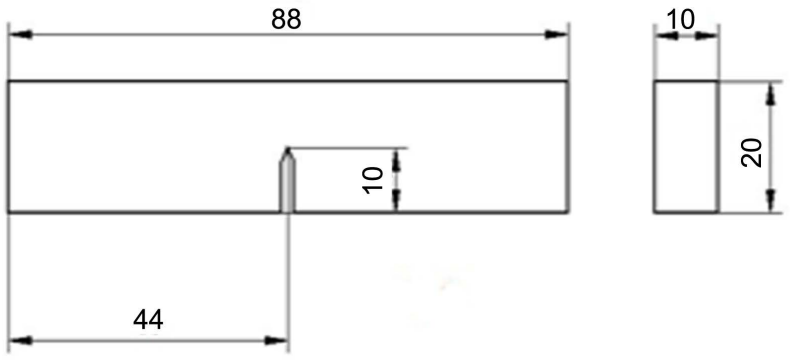

Figure 1. Single edge notch bending (SENB) samples as per ASTM 5045 (all dimensions are in mm).

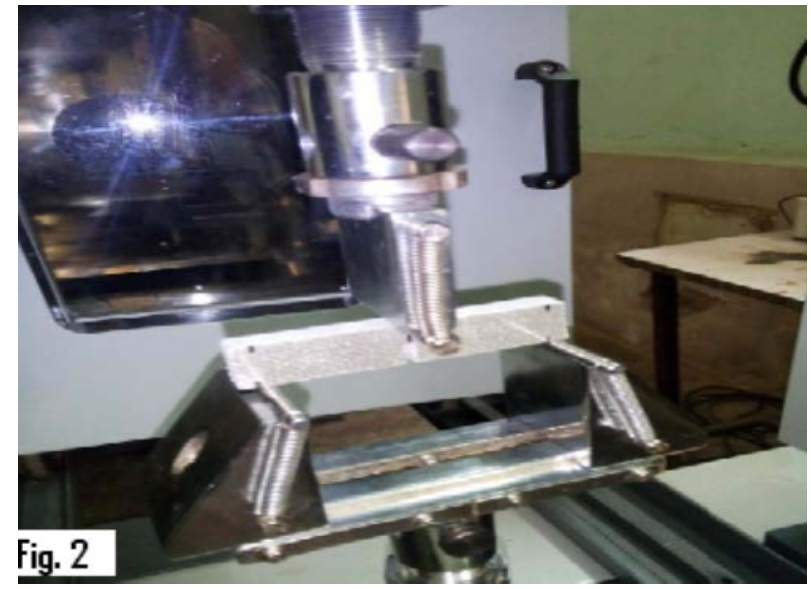

Figure 2. Universal Testing Machine showing the sample in position.

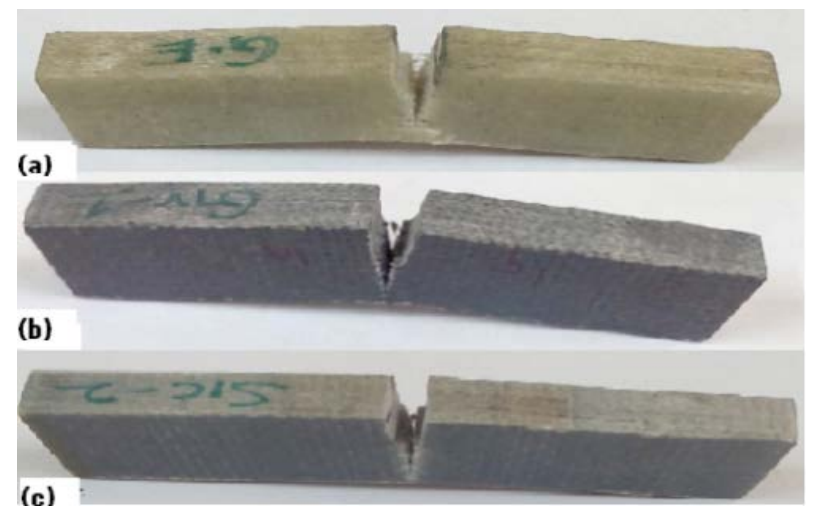

Figure 3. Photographs of the failed SENB specimens: (a) unfilled G-E, (b) graphite filled G-E, (c) SiC filled G-E composites.

tensile strength, which indicates that it is because of good adhesion between filler/ fiber with the epoxy matrix. The stress is transferred from the epoxy matrix to the filler in addition to the main load bearing glass fibers.

The addition of SiC/graphite increased the tensile strength of G-E when compared to unfilled G-E composite. This is possible only if the interface between the epoxy and filler is stronger. However, the interaction between the particle size distribution and the loading of SiC/graphite is extremely important. Among the two fillers selected in this study, the inclusion of silane treated SiC showed maximum tensile strength of about $404 \mathrm{MPa}$. There can be two reasons for the increasing trend in the strength of these hybrid composites compared to the unfilled G-E. One possibility was that the chemical reaction at the interface between the filler particles and the ma- 
Table 2. Mechanical properties of unfilled and particulate filled G-E composites.

\begin{tabular}{|c|c|c|c|c|c|}
\hline Composites & $\begin{array}{l}\text { Tensile strength } \\
\text { (MPa) }\end{array}$ & $\begin{array}{l}\text { Tensile modulus } \\
\text { (GPa) }\end{array}$ & $\begin{array}{l}\text { Flexural Strength } \\
(\mathrm{MPa})\end{array}$ & $\begin{array}{l}\text { Flexural modulus } \\
\text { (MPa) }\end{array}$ & Impact strength $(\mathrm{J} / \mathrm{m})$ \\
\hline G-E & $305.4 \pm 2$ & $12.62 \pm 0.5$ & $334.22 \pm 3$ & $21.23 \pm 2$ & $1350 \pm 5$ \\
\hline $5 \mathrm{Gr}+\mathrm{G}-\mathrm{E}$ & $342.1 \pm 3$ & $12.78 \pm 0.2$ & $464.13 \pm 3$ & $26.58 \pm 2$ & $885 \pm 3$ \\
\hline $10 \mathrm{Gr}+\mathrm{G}-\mathrm{E}$ & $355.8 \pm 5$ & $12.91 \pm 0.1$ & $475.22 \pm 4$ & $26.94 \pm 3$ & $918 \pm 3$ \\
\hline $5 \mathrm{SiC}+\mathrm{G}-\mathrm{E}$ & $402.2 \pm 3$ & $13.05 \pm 0.2$ & $469.72 \pm 4$ & $25.35 \pm 1$ & $650 \pm 2$ \\
\hline $10 \mathrm{SiC}+\mathrm{G}-\mathrm{E}$ & $404.2 \pm 6$ & $13.11 \pm 0.2$ & $455.84 \pm 2$ & $25.33 \pm 1$ & $710 \pm 2$ \\
\hline
\end{tabular}

trix may be too strong to transfer the tensile stress; the other was that the corner points of the irregular shaped particulates due to the size reduction $(<25 \mu \mathrm{m})$ resulted in less stress concentration in the polymer matrix. These two factors were responsible for increasing the tensile strengths of the hybrid composites so significantly. The compatibility of graphite particles in G-E seems to be not as good as that of SiC, as a result of which the percentage increasing in tensile strength was highest in SiC filled hybrid composites. The tensile modulus of all hybrid composites was also found to be marginally higher than that of unfilled G-E composite. Furthermore, the experimental results suggest that with addition of hard SiC filler into G-E showed superior tensile properties. However, in the present work, hard SiC and soft graphite micron-sized fillers were reinforced in G-E and expected to provide reasonable load bearing capacity. From Table 2, it seems that the introduction of SiC and graphite in G-E increases the tensile strength and tensile modulus. To explain this feature, we used salient fractured features noticed on tension test failed specimen by scanning electron microscopy.

From Figure 4, it can be seen that for unfilled G-E specimen, the failure process initiate first from the matrix layer (marked "C" in Figure 4(a)) of the specimen and is followed by few failure of fibers oriented in the loading direction (Figure 4(b)) and latter catastrophic failure was noticed (Figure 4(a)). It was further noticed that a process of matrix fracture and fiber-matrix debonding and bending of fibers oriented in the transverse direction (marked "B" in Figure 4(a)). However in SiC filled G-E specimens the failure region has noticeable fiber pull-out features (Figure 5(b)). This is in addition to the matrix cracking and fiber debonding noticed with the other filler-free specimens (Figure 5(a)). It should be pointed out that the presence of SiC does not alter the degree of cross linking of the epoxy matrix. However, the surface area effect brought in the reinforcement enhancing the adhesion has been proved to be a beneficial factor in G-E composites. Hence these may indirectly participate and enhanced the strength and modulus of G-E composites.

\subsubsection{Flexural Properties}

The static flexural strength of unfilled and particulate filled hybrid composites was listed in Table 2. It was seen that the particulate filler additions improved the flexural strength of the unfilled G-E composite. The highest flexural strength was found for the $10 \mathrm{wt} \%$ graphite filled G-E composite. The flexural strength of the G-E composite increased with increasing $\mathrm{SiC} /$ graphite loading. In order to reach the best flexural strength, the optimal content of $10 \mathrm{wt} \%$ graphite particles in the G-E composite is recommended.

Under flexural loading condition, fillers act as load bearing materials rather than act as stress raisers. This is due to compressive stresses tends to close cracks and flaws that are perpendicular to the applied stress, contrary to the crack opening mechanism occurring in a tensile loading situation [35]. It is well known that bearing failure occurs in the material immediately adjacent to the contact area between the fastener and the laminate and is caused primarily by compressive stresses acting on the surface. Hence, G-E composite with $10 \mathrm{wt} \%$ graphite particle content have lower bearing strength than that of G-E composite with $5 \mathrm{wt} \%$ graphite particle content. The presence of agglomeration in the G-E composites obviously deteriorates their mechanical properties. Agglomerations may easily happen for smaller particles at higher filler contents due to the reduced inter-particle distance. In the current study, it shows different behavior for different fillers loaded G-E composites. For example, $10 \mathrm{wt} \%$ graphite filled G-E composite have higher flexural strength and modulus of 475.22 MPa and 26.94 GPa respectively. This may be due to the lubricating filler used as well as adhesion and uniform dispersion between the filler and matrix.

Polymer based composites when subjected to impact type of loading conditions, energy is absorbed in the process of plastic deformation of matrix material, debonding at matrix/reinforcement interface and in the frac- 


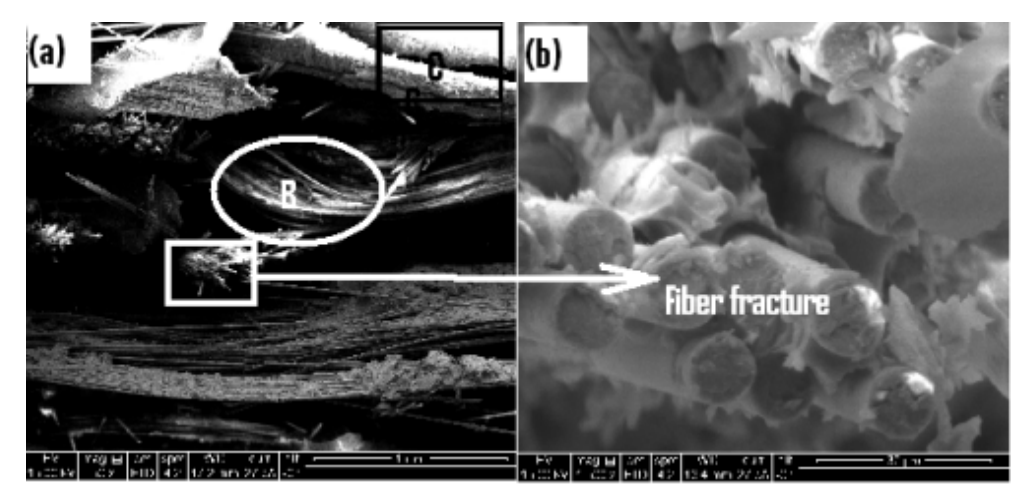

Figure 4. SEM micrographs of unfilled filled G-E failed specimens under tensile testing: (a) Lower magnification $50 \times$ (b) Higher magnification $1500 \times$.

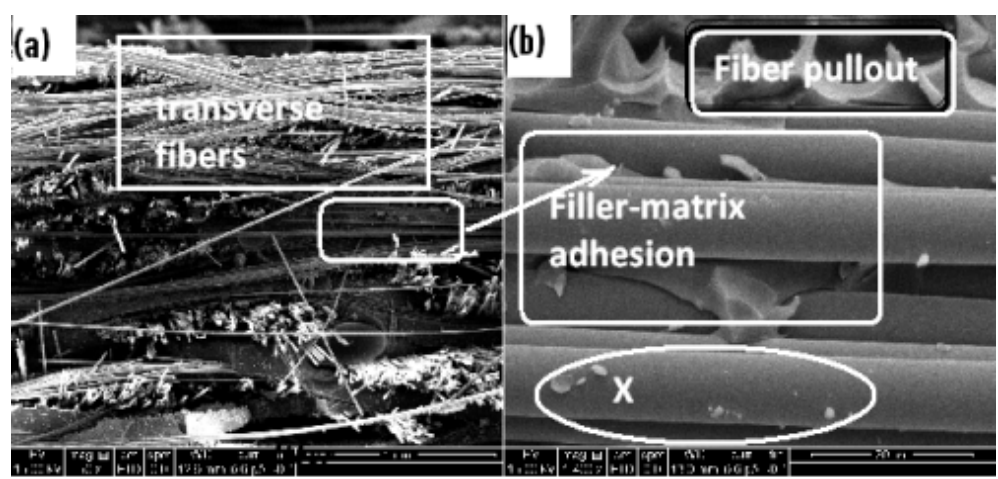

Figure 5. SEM micrographs of SiC filled G-E failed specimens under tensile testing: (a) Lower magnification 50× (b) Higher magnification 1500×.

ture of reinforcing material. The phenomenon that absorbs least amount of energy for its occurrence becomes prominent and leads to fracture. In case when small particles are incorporated in the matrix, crack length increases considerably during the process of fracture. For the same volume fraction of the filler, the smaller the size of filler particles, the larger will be the surface area; hence higher will be the increase in crack length leading to increase in energy absorption before fracture. If the compatibility of the filler particles with the matrix material is not good, the crack blunting at the filler particle location will play an important role and again leads to the same conclusion.

The failure of a polymer matrix composite is dependent on a) the constituent materials, b) the shape of materials and their alignment within the matrix and c) the type of loading experienced in a specific direction. Under bending load, common failures include: compressive failure, tensile failure, shear and/or delamination and SEM pictures of failed samples are shown in (Figures 6-8). Delamination is the fracture along the direction of the fiber and is indicated by a laminate layer being separated from the G-E composite (Figure 6(a) and Figure 6(b)). The other forms of failures generally occur in the transverse direction because bidirectional composites are obviously anisotropic. Tensile failures are uncommon in flexural tests due to the strong tensile properties of the glass fibers. Should a composite fail in tension, it can be due to brittle failure or fiber pullout as shown in (Figure 6(b)). Failures in compression are the most common and each specimen is likely to fail in this manner (Figures 6-8). Kinking is the most predominant form of compressive failure. However, composites may also fail due to micro-buckling, shear or splitting. Various features of failed samples are documented in the SEM micrographs.

\subsubsection{Impact Strength}

Results of the impact test of unfilled and particulate filled G-E composites are listed in Table 2. Remarkable difference in the impact strength of the G-E composite can be seen with the addition of two types of fillers. The impact strength has decreased by about 32\% with $10 \mathrm{wt} \%$ graphite in G-E composite. In case of graphite filled 


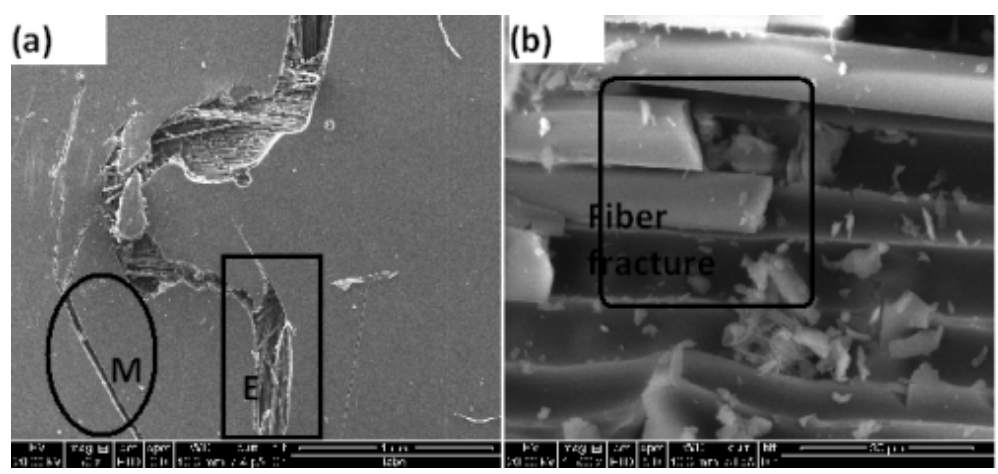

Figure 6. SEM micrographs of unfilled G-E failed specimens under flexural testing: (a) Lower magnification 50× (b) Higher magnification 1500×.

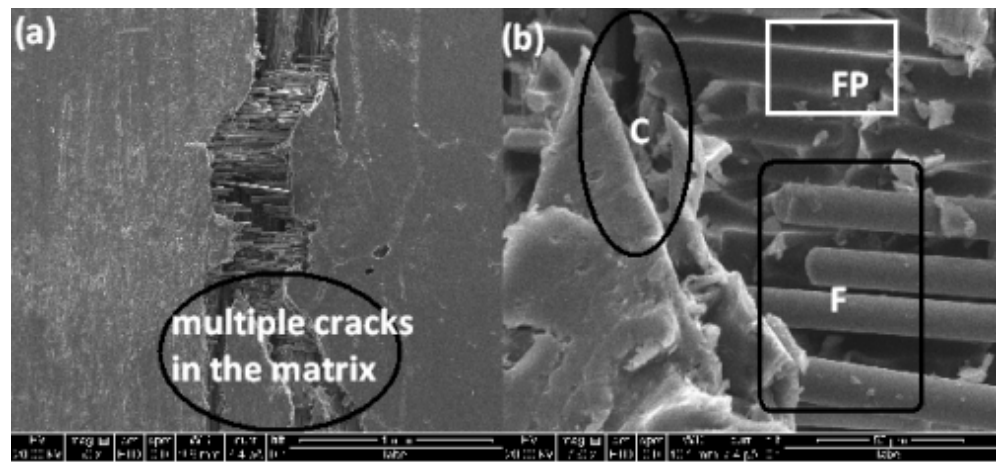

Figure 7. SEM micrographs of SiC filled G-E failed specimens under flexural testing: (a) Lower magnification 50× (b) Higher magnification 1500×.

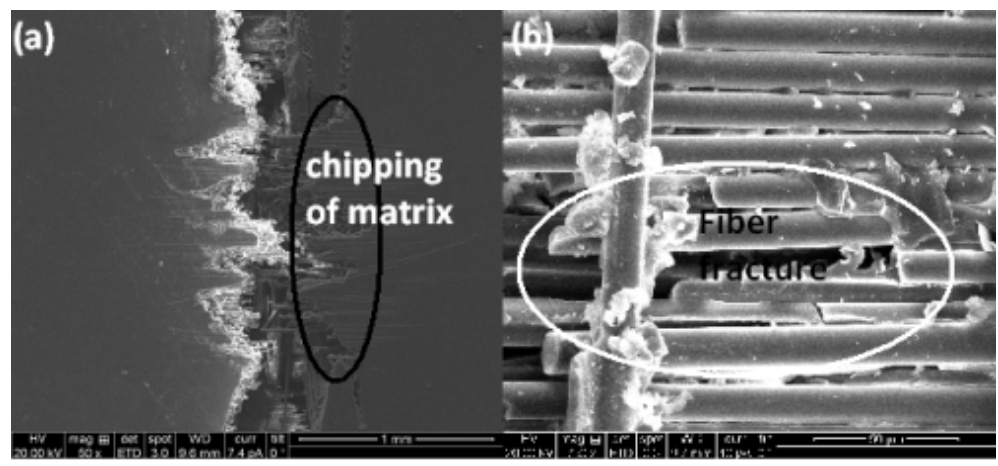

Figure 8. SEM micrographs of graphite filled G-E failed specimens under flexural testing: (a) Lower magnification 50× (b) Higher magnification 1500×.

G-E sample, filler compatibility with the matrix resin seems to be not good. This validates the poor impact strength obtained by graphite filled G-E composites. Addition of hard SiC filler further reduced the impact strength of G-E composites. The reduction in impact strength is maximum and of about $52 \%$. Because of voids during the hand lay-up method, these voids increase the crack propagation, typically a polymer matrix with high loading of filler has less ability to carry the impact energy. Higher loading of hard fillers disturb the matrix continuity leading to stress concentrations, which can act as micro-crack initiator and reduce the adhesion and energy absorption capacity of composites.

\subsection{Fracture Toughness}

In the current study, the crack growth of filled and unfilled samples are shown in (Figures 3(a)-(c)) the fracture 
and damage regions of composites in the notch tip zone are clearly seen some micro-cracks are formed and increase very slowly. The increase in load cause initiation of the crack in the composite and transverse cracking occur along the different layers and some longitudinal cracking along the composite layers near the crack tip. The first matrix cracking occur and fiber bundle unit fracture follows. The loading level reaches maximum $\mathrm{P}_{\max }$. It was noticed that at this loading level, no fiber damage was detected.

The typical load versus deflection curves for unfilled and particulate filled G-E composite samples are shown in (Figure 9 and Figure 10) respectively.

All load-deflection curves have an initially linear response, which becomes progressively non-linear and load drops which indicates fast stable crack growth because of additional crack opening displacement is not required for crack propagation. The crack initially propagates stable manner and eventually unstable manner at maximum load. It is also clear from the figures that the highest and lowest peak load were found in $5 \mathrm{wt} \%$ graphite and un-

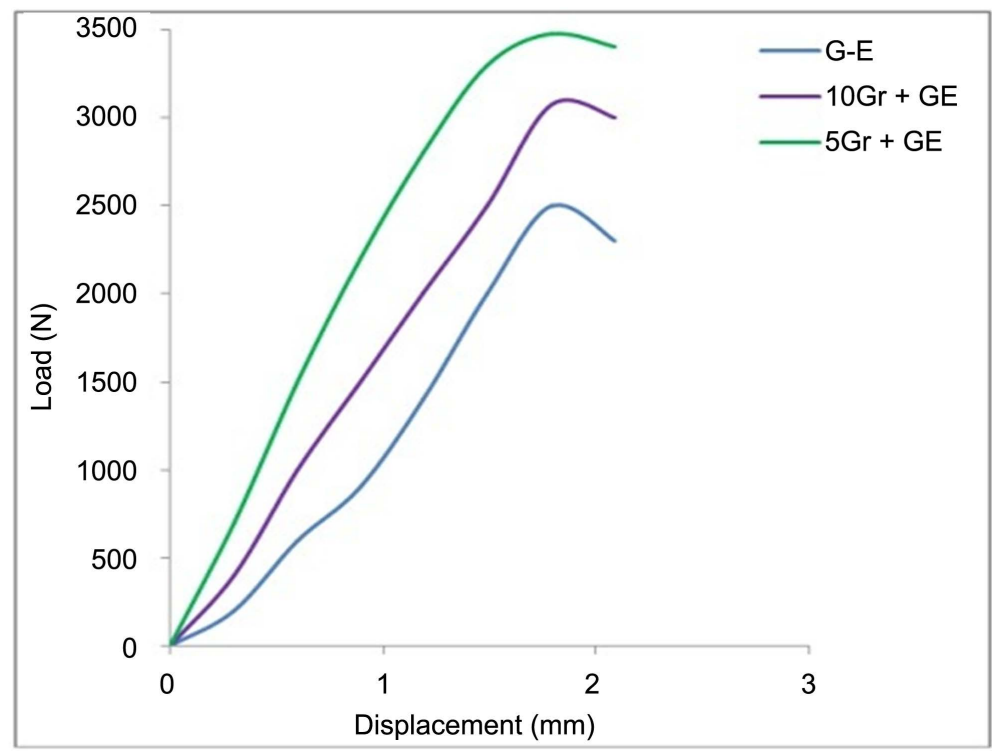

Figure 9. Load-displacement curves for unfilled and graphite filled G-E composites.

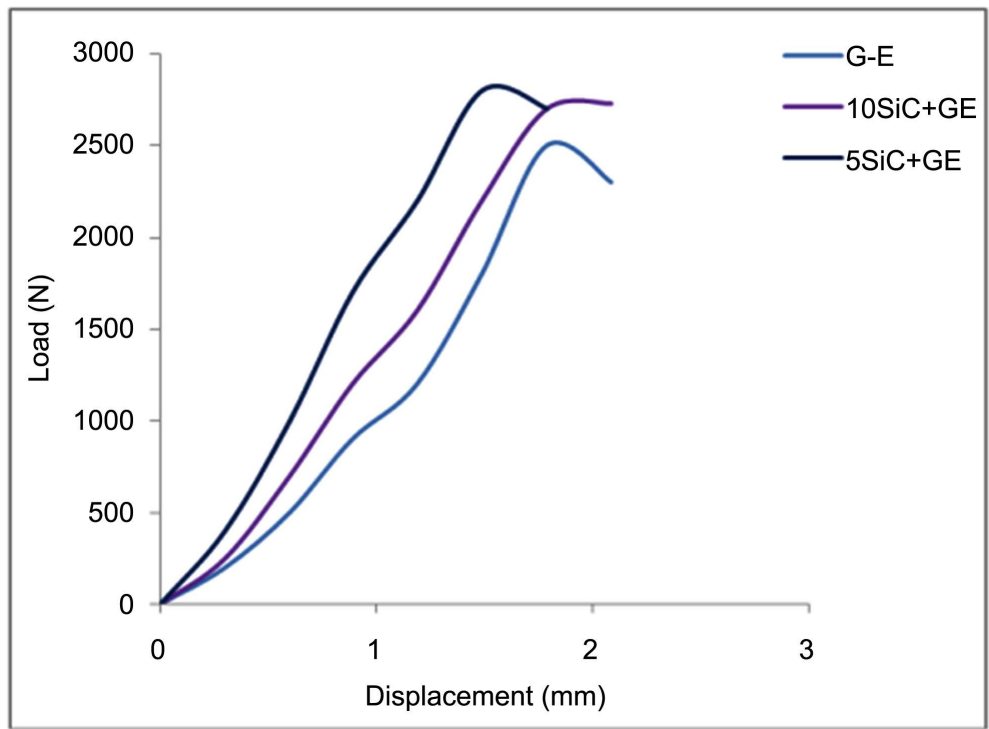

Figure 10. Load-displacement curves for unfilled and SiC filled G-E composites. 
filled G-E composites respectively. Even though $5 \mathrm{wt} \% \mathrm{SiC}$ filled composite has taken lesser load, the graph plot indicates that the failure has occurred after undergoing a deflection of about $1.8 \mathrm{~mm}$ which is more than that of unfilled G-E. The specimen $5 \mathrm{wt} \%$ graphite has a carried load of $3476 \mathrm{~N}$, where as the specimen with $10 \mathrm{wt} \%$ graphite shows a drop of less than $400 \mathrm{~N}$. The probable cause is that graphite particles pin the crack and inhibit its propagation, hence the low deformation.

For the unfilled G-E composite, the $\mathrm{K}_{\mathrm{IC}}$ value is less than that of particulate filled G-E composites. The incorporation of graphite increased the fracture toughness of G-E composite. However, addition of hard SiC and lubricating graphite can efficiently enhance the G-E toughness. When the lubricating graphite was utilized to modify the G-E, a significant toughening effect was found in the G-E; however, the incremental increase in the $\mathrm{SiC}$ filled G-E composite is not so significant. Once hard SiC particles were introduced into G-E, since the fracture toughness of G-E is $23 \mathrm{MPa} \mathrm{m}^{1 / 2}$, the function of SiC particles is destructive.

From Figure 11, it is observed that G-E with 5 wt\% graphite has the maximum $\mathrm{K}_{\mathrm{IC}}$ value $28.7 \mathrm{MPa} \mathrm{m}^{1 / 2}$ closely followed the one with $10 \mathrm{wt} \%$ graphite $27.2 \mathrm{MPa} \mathrm{m}^{1 / 2}$. This can be attributed to the higher filler loading into G-E causes pining effect and hence the reduced the toughness of the matrix. Similar observations were also found in literature [28] [29]. The specimen with 5 and $10 \mathrm{wt} \% \mathrm{SiC}$ has $\mathrm{K}_{\mathrm{IC}}$ value of 25.5 and $23.92 \mathrm{MPa} \mathrm{m}^{1 / 2}$ respectively. Among all the composites tested, graphite filled G-E composites showed the maximum fracture toughness.

In light of the hybrid composites studied, it is suggested that lubricating filler like graphite and hard SiC fillers have positive influence on the fracture toughness of G-E composite. Although soft graphite particles can provide the better fracture toughness, the overall mechanical properties such as strength and stiffness are inferior to that of SiC filled G-E composites.

\subsection{Fractography of Composites}

The SEM micrographs of fractured features for SENB failed samples are shown in (Figures 12-14). From micrographs of G-E sample shown in (Figure 12(a) and Figure 12(b)), it can be seen that evidence of matrix deformation, matrix cracking, fiber debonding, fiber fracture and pullout of fibers occurred along the longitudinal direction. Fractured and fiber pulled-out cavities (Figure 12(b)) were also seen from the micrograph. Fracture surface of composites were analyzed and compared to that of neat epoxy. For graphite filled G-E samples, fractured features were marked in the micrographs (Figure 13(a) and Figure 13(b)). Good bonding between the fiber/filler-matrix can be seen. Multiple fractures of fiber, instantaneous fracture of fibers and all transverse fibers well bonded with the matrix are the additional features that can be noticed from SEM picture (Figure 13(b)). The ductility is increased in filler filled samples as evidenced by the smaller deformation compared to unfilled

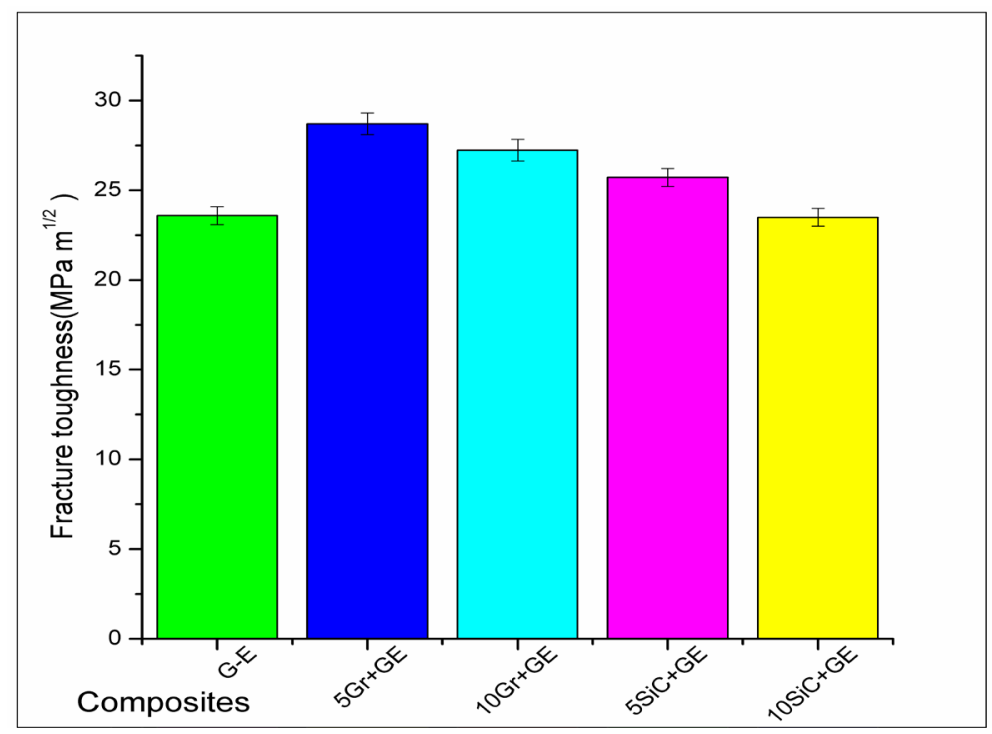

Figure 11. Fracture toughness data of unfilled, graphite and SiC filled G-E composites. 
G-E sample. It can be concluded that this soft filler increased the ductility of the matrix also contribute the increasing of fracture toughness. For SiC filled G-E composites fractured features shown in (Figure 14(a) and Figure 14(b)) are almost similar to graphite filled G-E composites except fiber pullout, more voids and severe matrix damage. These SEM observations are in good agreement with the fracture toughness test data shown in (Figure 11).

\section{Conclusions}

In this work, an experimental investigation has been made to evaluate the mechanical properties and fracture toughness of unfilled and particulate filled G-E hybrid composites. The results show that it is possible to fabricate successfully, multi-component hybrid composites (three different constituents) for structural applica-

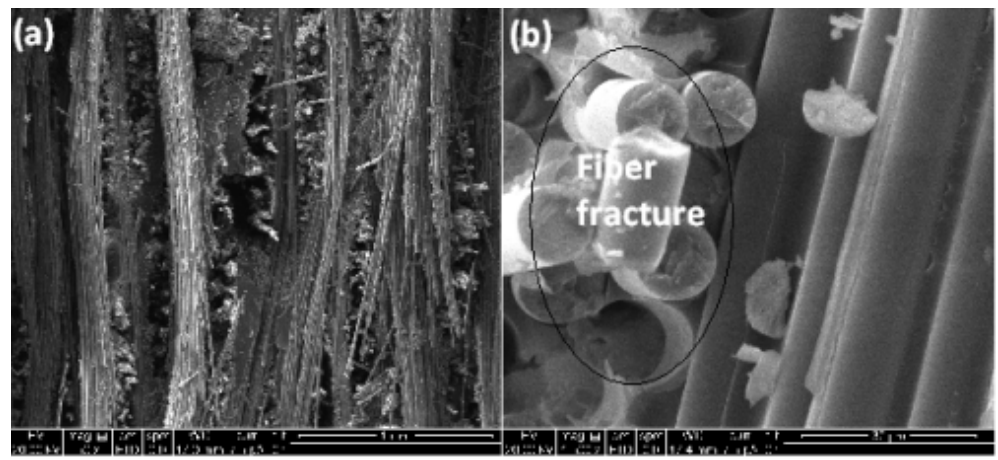

Figure 12. SEM micrographs of unfilled G-E fractured SENB specimens: (a) Lower magnification 50× (b)Higher magnification 1500×.

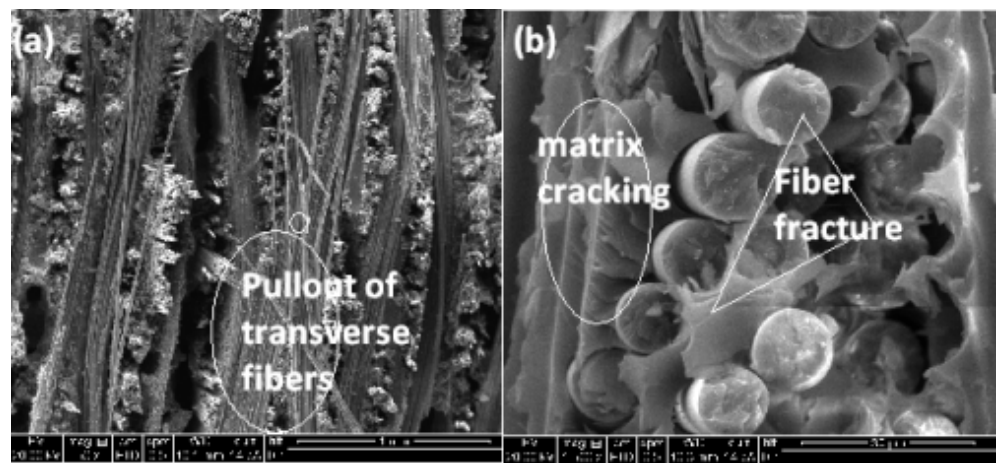

Figure 13. SEM micrographs of graphite filled G-E fractured SENB specimens: (a) Lower magnification 50× (b) Higher magnification 1500×.

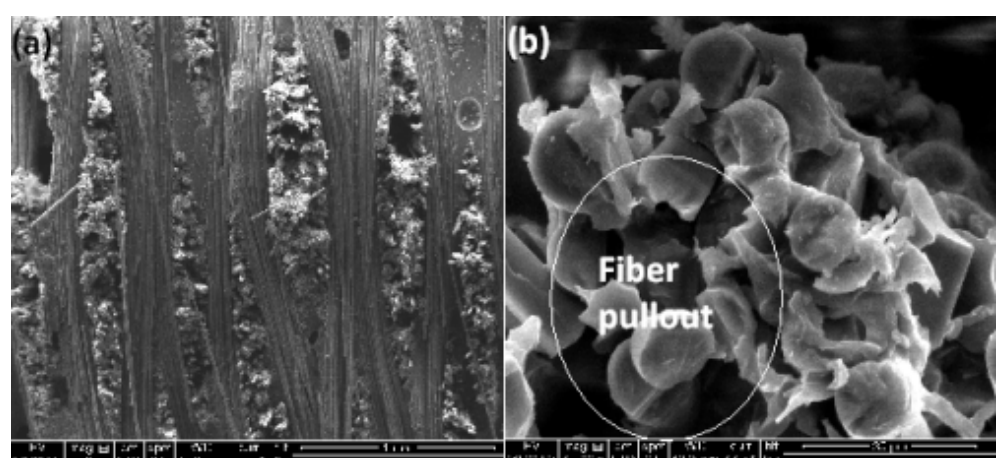

Figure 14. SEM micrographs of SiC filled G-E fractured SENB specimens: (a) Lower magnification 50× (b) Higher magnification 1500×. 
tions. The following conclusions can be drawn from this study.

Hard and lubricating fillers viz. SiC and graphite particles modify the mechanical properties of G-E composite. Addition of filler loading (5 to $10 \mathrm{wt} \%$ ) led to an increase in tensile and flexural properties. Particulate filled G-E hybrid composites show that the large difference between fiber-matrix interfacial bonding and the type of filler can influence the complex stress concentrations around the fibers. In this work, SiC filled G-E hybrid composites exhibit significant improvement in tensile and flexural properties.

The impact resistance depends on the complex energy dissipation mechanisms, in which the interface properties and the complex stress concentration of the type and size of particles and geometry of the fibers play an important role on the control of the composite fracture. Both fillers did not show improvement in the impact strength of G-E composite.

The fracture energy of the G-E composites has been improved by both $\mathrm{SiC}$ as well as with lubricating graphite particles. Rigid nature of SiC particles leading to effective relief of crack-tip triaxial stress, small scale yielding of epoxy matrix and stretching of $\mathrm{SiC}$ particles were facilitated in the crack tip region leading to improved fracture toughness of G-E hybrid composite. Furthermore, the hard SiC particles in G-E, the fracture toughness is marginal. On the contrary, the lubricating filler additions, i.e. graphite into G-E, show the maximum fracture energy.

By considering the overall mechanical performance, G-E composite modified with lubricating graphite particles demonstrates the superior performance and the same composition may be utilized for fabrication of structural load bearing components.

SEM micrographs reveal features like micro-cracks in the matrix, bending of transverse fibers, fiber pullout, fiber breakage, and fiber-matrix debonding.

\section{Acknowledgements}

We would like to thank Mr. S. K. Sidhaye, Chief Executive Officer, Klpak Instruments \& Controls, Pune, India for providing the testing facilities. The authors are thankful to the Management and Principal Dr. G. L. Shekar, The National Institute of Engineering, Mysore for their encouragement.

\section{References}

[1] Ferrigno, T.H. (1987) Principles of Filler Selection and Use. In: Katz, H.S. and Milewski, J.V., Eds., Van Nostrand Reinhold, New York, 80-97.

[2] Suresha, B., Chandramohan, G. and Renukappa, N.M. (2007) Mechanical and Tribological Properties of Glass-Epoxy Composites with and without Graphite Particulate Filler. Journal of Applied Polymer Science, 103, 2472-2480. http://dx.doi.org/10.1002/app.25413

[3] Suresha, B., Chandramohan, G. and Sadananda Rao, P.R. (2007) Influence of SiC Filler on Mechanical and Tribological Behavior of Glass Fabric Reinforced Epoxy Composite Systems. Journal of Reinforced Plastics and Composites, 26, 565-578. http://dx.doi.org/10.1177/0731684407075533

[4] Ashby, M. (1999) Material’s Selection in Mechanical Design. 2nd Edition, Butterworth Heinemann, Oxford.

[5] Chen, X. and Chandra, N. (2004) The Effect of Heterogeneity on plane Wave Propagation through Layered Composites. Composites Science and Technology, 64, 1477-1493. http://dx.doi.org/10.1016/j.compscitech.2003.10.024

[6] Dekkers, M.E. and Heikens, D. (1988) The Effect of Interfacial Adhesion on the tensile Behavior of PolystyreneGlass-Bead Composites. Journal of Applied Polymer Science, 28, 3809-3815. http://dx.doi.org/10.1002/app.1983.070281220

[7] Radford, K.C. (1971) The Mechanical Properties of an Epoxy Resin with a Second Phase Dispersion. Journal of Materials Science, 6, 1286-1291. http://dx.doi.org/10.1007/BF00552042

[8] Amdouni, N., Sautereau, H. and Gerard, J.F. (1992) Epoxy Composites Based on Glass-Beads. 2. Mechanical-Properties. Journal of Applied Polymer Science, 46, 1723-1735. http://dx.doi.org/10.1002/app.1992.070461004

[9] Fu, S.Y and Lauke, B. (1998) Characterization of Tensile Behavior of Hybrid Short Glass Fiber Calcite Particle ABS Composites. Composite Part A: Applied Science, 29, 575-583. http://dx.doi.org/10.1016/S1359-835X(97)00117-6

[10] Eirich, F.R. (1984) Some Mechanical and Molecular Aspects of the Performance of Composites. Journal of Applied Polymer Science, 39, 93-102.

[11] Fu, S.Y. and Lauke, B. (1997) Analysis of Mechanical Properties of Injection Molded Short Glass Fiber (SGF)/Calcite/ ABS Composites. Journal of Materials Science and Technology, 13, 389-396. http://serials.unibo.it 
[12] Spanoudakis, J. and Young, R.J. (1984) Crack Propagation in a Glass Particle Filled Epoxy-Resin. Effect of Particle-Volume Frtion and Size. Journal of Materials Science, 19, 473-486. http://dx.doi.org/10.1007/BF02403234

[13] Hsueh, C.H. (1989) Effects of Aspect Ratios of Ellipsoidal Inclusions on Elastic Stress Transfer of Ceramic Composites. Journal of American Ceramic Society, 72, 344-347. http://dx.doi.org/10.1111/j.1151-2916.1989.tb06132.x

[14] Zhu, Z.K., Yang, Y. and Yin, J. (1993) Preparation and Properties of Organ Soluble Polyimide/Silica Hybrid Materials by Sol-Gel Process. Journal of Applied Polymer Science, 73, 2977-2984. http://dx.doi.org/10.1002/(SICI)1097-4628(19990929)73:14<2977::AID-APP22>3.0.CO;2-J

[15] Young, R.J. and Beaumont, P.W. (1977) Effect of Composition upon Fracture of Silica Particle-Filled Epoxy-Resin Composites. Journal of Materials Science, 12, 684-692. http://dx.doi.org/10.1007/BF00548158

[16] Pukanszky, B. and Voros, G. (1993) Mechanism of Interfacial Interactions in Particulate Filled Composites. Composite Interfaces, 1, 411-427.

[17] Nakamura, Y., Yamaguchi, M. and Matsumoto, O.M. (1992) Effects of Particle Size on Mechanical and Impact Properties of Epoxy Resin Filled with Spherical Silica. Journal of Applied Polymer Science, 45, 1281-1289. http://dx.doi.org/10.1002/app.1992.070450716

[18] Danusso, F. and Tieghi, G. (1986) Strength versus Composition of Rigid Matrix Particulate Composites. Polymer, 27, 1385-1390. http://dx.doi.org/10.1016/0032-3861(86)90038-8

[19] Nicolais, L. and Narkis, M. (1971) Stress-Strain Behavior of Styrene-Acrylonitrile/Glass Bead Composites in the Glassy Region. Polymer Engineering and Science, 11, 194-199. http://dx.doi.org/10.1002/pen.760110305

[20] Moloney, A.C., Kausch, H.H. and Kaiser, T. (1987) Parameters Determining the Strength and Toughness of Particlate Filled Epoxide Resins. Journal of Materials Science, 22, 381-393. http://dx.doi.org/10.1007/BF01160743

[21] Shimbo, M., Ochi, M. and Shigeta, Y. (1981) Shrinkage and Internal Stress during Curing of Epoxide Resins. Journal of Applied Polymer Science, 26, 2265-2277. http://dx.doi.org/10.1002/app.1981.070260714

[22] Spanoudakis, J. and Young, R.J. (1984) Crack Propagation in a Glass Particle Filled Composite at or Near a Rigid Sphericalinclusion. Journal of Materials Science, 19, 487-496. http://dx.doi.org/10.1007/BF02403235

[23] Wang, W.X., Takao, Y. and Matsubara, T. (2002) Improvement of the Interlaminar Fracture Toughness of Composite Laminates by Whisker Reinforced Interlamination. Composites Science and Technology, 62, 767-774. http://dx.doi.org/10.1016/S0266-3538(02)00052-0

[24] Cho, J., Joshi, M.S. and Sun, C.T. (2006) Effect of Inclusion Size on Mechanical Properties of Polymer Composites with Micro and Nano Particles. Composites Science and Technology, 66, 1941-1952.

http://libra.msra.cn/Publication/40833973 http://dx.doi.org/10.1016/j.compscitech.2005.12.028

[25] Mishra, A.K., Mohanty, L. and Drzal, T. (2003) Studies on Mechanical Performance of Biofibre/Glass Reinforced Polyester Hybrid Composites. Composites Science and Technology, 63, 1377-1385. http://dx.doi.org/10.1016/S0266-3538(03)00084-8

[26] Dong, J. and Ian, D. (2014) Flexural and Tensile Moduli of Unidirectional Hybrid Epoxy Composites Reinforced by S-2 Glass and T700S Carbon Fibers. Materials and Design, 54, 893-899. http://dx.doi.org/10.1016/j.matdes.2013.08.086

[27] Avci, A., Arikan, H. and Akdemir, A. (2004) Fracture Behavior of Glass Fiber Reinforced Polymer Composite. Cement and Concrete Research, 34, 429-434. http://www.researchgate.net/publication/223649765 http://dx.doi.org/10.1016/j.cemconres.2003.08.027

[28] Srivastava, V.K. and Shembekar, P.S. (1999) Tensile and Fracture Properties of Epoxy Resin Filled with Fly Ash Particle. Journal of Materials Science, 25, 3513-3516. http://link.springer.com/article/10.1007\%2FBF00575379 http://dx.doi.org/10.1007/BF00575379

[29] Srivastava, V.K., Shembker, P.S. and Prakash, R. (2005) Fracture Behavior of Fly Ash Filled FRP Composites of Glass Filled Epoxy. Journal of Materials Science, 53, 1167-1178.

[30] Leonard, W.H., Low, K.O. and Yousi, K.F. (2009) Fracture Behavior of Glass Fiber-Reinforced Polyester Composite. Journal of Materials: Design and Applications, 83, 223-228.

[31] Molony, A.C. and Kausch, H.H. (1983) Effect of Particle on Fracture Toughness of Epoxy Resin Filled with Spherical Silica. Journal of Materials Science, 18, 208-216. http://link.springer.com/journal/10853 http://dx.doi.org/10.1007/BF00543827

[32] Harikainen, J., Hine, P. and Szabo, J.S. (2004) Polypropylene Hybrid Composites Reinforced with Long Glass Fibers and Particulate Filler. Journal of Composites Science and Technology, 65, 257-267.

http://libra.msra.cn/Publication/40833780

http://dx.doi.org/10.1016/j.compscitech.2004.07.010 
[33] Naveed, S.A., Ricky Woo, S.C. and Jang, K.K. (2007) Mode-I Interlaminar Fracture Behavior and Mechanical Properties of CFRPs with Nanoclay-Filled Epoxy Matrix. Composites Part A: Applied Science and Manufacturing, 38, 449456. http://www.researchgate.net/publication/222427919 http://dx.doi.org/10.1016/j.compositesa.2006.03.001

[34] Soon, C.K., Taduharu, A. and Wakoka, A. (2008) Effect of Composing Particles of Two Sizes on Mechanical Properties of Spherical Silica-Particulate-Reinforced Epoxy Composites. Composites Part B: Applied Science and Manufacturing, 39, 740-746. http://dx.doi.org/10.1016/j.compositesb.2007.02.030

[35] Hagstrand, P.O., Bonjour, F. and Manson, A.E. (2005) The Influence of Void Content on the Structural Flexural Performance of Unidirectional Glass Fiber Reinforced Polypropylene Composites. Composites Part A: Applied Science and Manufacturing, 36, 705-714. http://dx.doi.org/10.1016/j.compositesa.2004.03.007 